Jurnal Sulolipu : Media Komunikasi Sivitas Akademika dan Masyarakat

Vol. 20 No. 12020

e-issn : 2622-6960, p-issn : 0854-624X

\title{
HUBUNGAN KONDISI SARANA SANITASI LINGKUNGAN DENGAN KEJADIAN DIARE DI LEMBAGA PERMASYARAKATAN PEREMPUAN KELAS II A SUNGGUMINASA
}

Irana Dewi Marjuni, Sulasmi

Jurusan Kesehatan Lingkungan Politeknik Kemenkes Makassar

ranadewi89@gmail.com

\section{ABSTRACT}

Diarrhea is an endemic disease in Indonesia and also a potential disease of Extraordinary Events (KLB) which often causes death. Diarrhea in the Gowa Regency area with the number of diarrhea patients treated was 16,450 cases $(88.7 \%)$ out of 18,553 cases of discovery targets. This research aims to know the relation between the condition of environmental sanitation facilities and incidents of diarrhea in Class II A Sungguminasa Women's Correctional. This type of research is analytical observation research with a cross-sectional approach where independent variables and dependent variables are examined simultaneously to find the relationship between these variables. The sampling technique is purposive sampling, then the data are analyzed using the chi-square test. The results showed there are no relationship between clean water facilities and the incidence of diarrhea $(p=-)$, toilet facilities with the incidence of diarrhea $(p=0.967)$, garbage shelter facilities with the incidence of diarrhea $(p=0.519)$, and wastewater disposal facilities with diarrhea incidence $(p=0.747)$. From this research, the conclusion is there are no variables associated with the incidence of diarrhea in Class II A Sungguminasa Women's Correctional Institution.

Keywords: Diarrhea, Clean Water, Toilet, Garbage Shelter, Wastewater disposal

\section{ABSTRAK}

Penyakit diare merupakan penyakit endemis di Indonesia dan juga merupakan penyakit potensi Kejadian Luar Biasa (KLB) yang sering disertai dengan kematian.Penyakit diare di wilayah Kabupaten Gowa dengan jumlah penderita diare ditangani sebanyak 16.450 kasus (88,7\%) dari 18.553 kasus target penemuan. Tujuan penelitian ini untuk mengetahui hubungan kondisi sarana sanitasi lingkungan dengan kejadian diare di Lembaga Permasyarakatan Perempuan Kelas II A Sungguminasa. Jenis penelitian ini adalah penelitian observasi analitik dengan pendekatan cross sectional dimana variabel bebas dan variabel terikat diteliti secara bersamaan guna mengetahui hubungan antara variabel-variabel tersebut. Teknik pengambilan sampel yaitu proposive sampling, kemudian data dianalisis menggunakan uji chi square. Hasil penelitian menunjukkan tidak ada hubungan antara sarana air bersih dengan kejadian diare $(p=-)$, sarana jamban dengan kejadian diare $(p=0,967)$, sarana penampungan sampah dengan kejadian diare $(p=0,519)$, dan sarana pembuangan air limbah dengan kejadian diare $(p=0,747)$. Dari penelitian ini disimpulkan bahwa tidak ada variabel yang berhubungan dengan kejadian diare di Lembaga Permasyarakatan Perempuan Kelas II A Sungguminasa.

Kata kunci : Diare, Air Bersih, Jamban, Penampungan Sampah, Pembuangan Air Limbah

\section{PENDAHULUAN}

Ketersediaan sarana sanitasi di lembaga permasyarakatan perempuan kelas II A Sungguminasa, sarana air bersih yang digunakan setiap harinya menggunakan air dari PDAM, dalam satu kamar terdapat satu sarana jamban dan setiap kamar memiliki penghuni melebihi kapasitas kamar, sarana penampungan sampah yang digunakan dalam setiap kamar memiliki 2 tempat sampah yang terbuat dari drum ada yang tertutup dan ada juga yang tidak tertutup dan setiap harinya sampah yang dihasilkan dibuang kebelakang kantor, dan untuk sarana pembuangan air limbah tidak dilakukan pengolahan terlebih dahulu, limbah yang

$$
\text { Angka Kesakitan (Morbiditas) }
$$

Penyakit diare di wilayah sulawesi selatan adalah khususnya di Kota Makassar kasus diare ditemukan dan ditangani yang dilaporkan oleh 46 puskesmas se Kota Makassar sampai dengan Desember 2015 sebanyak 28.257 kasus dengan angka kesakitan yaitu 20,07 per 1.000 penduduk meningkat dari tahun 2014 yaitu 26.485 kasus dengan angka kesakitan yaitu 19,34 per 1.000 penduduk (Profil Kesehatan Makassar, 2015)

Penyakit diare di wilayah Kabupaten Gowa dengan jumlah penderita diare ditangani sebanyak 16.450 kasus (88,7\%) dari 18.553 kasus target penemuan. Pada tahun 2016 jumlah penderita diare yang ditangani menurun dibadingkan pada tahun 2015, hal ini dikarenakan angka kesakitan diare per 1000 penduduk bertambah dari 214 menjadi 270 pada tahun 2016 dan jumlah target yang bertambah sebanyak $10 \%$ pada tahun 2015 menjadi $20 \%$ dari jumlah penduduk pada tahun 2016. (Profil Kesehatan Kabupaten Gowa, 2016)

Berdasarkan data penyakit tahun 2018 di klinik lembaga permasyarakatan perempuan klas II A Sungguminasa mempunyai angka kejadian diare yang ketiga dari beberapa penyakit berbasis lingkungan dengan jumlah 105 penderita diare 


\section{METODE}

1. Lokasi

$$
\begin{aligned}
& \text { Penelitian ini dilakukan di } \\
& \text { Lembaga } \\
& \text { Perempuan Kelas II A Sungguminasa. }
\end{aligned}
$$

2. Waktu

Tahap persiapan meliputi observasi, menyusun proposal yang berlangsung pada bulan Desember 2018 sampai Januari 2019. Tahap pelaksanaan meliputi kegiatan yang berlangsung pada bulan Februari - Mei 2019.

\section{Jumlah dan cara pengambilan subjek}

Sampel dalam penelitian ini dengan jumlah 54 orang yang diambil secara proposive sampling dengan rincian setiap kamar diambil sebanyak 2 orang. Teknik sampling menggunakan proposive sampling berdasarkan kriteria :

a. Bersedia menjadi responden.

b. Perwakilan dalam satu kamar.

\section{Jenis dan Cara Pengumpulan Data}

1. Wawancara (Interview)

Metode yang digunakan untuk mengumpulkan data, dimana peneliti mendapatkan keterangan secara lisan dari seorang responden atau becakapcakap berhadapan muka dengan responden.

2. Pengamatan (Observasi)

Metode yang digunakan untuk mengumpulkan data, dimana peneliti mendapatkan keterangan dengan melihat dan mencatat kondisi yang ada hubungannya dengan masalah yang akan diteliti.

\section{Pengolahan dan analisis data}

Data yang diperoleh dari hasil observasi dilapangan dan wawancara diolah secara komputer yang kemudian disajikan dalam bentuk tabel. Analisis data ditentukan untuk mengetahui hubungan antara variabel bebas dan variabel terikat. Selain itu, analisis data yang digunakan dalam penelitian ini adalah analisis univariat dan analisis bivariat.

\section{HASIL}

1. Analisis Deskriptif
Tabel 1

Distribusi Kondisi Sarana Air Bersih Lembaga Permasyarakatan Perempuan Kelas II A Sungguminasa Tahun 2019

\begin{tabular}{cccc}
\hline No & $\begin{array}{c}\text { Sarana Air } \\
\text { Bersih }\end{array}$ & $\mathbf{n}$ & $\%$ \\
\hline $\mathbf{1}$ & $\begin{array}{c}\text { Tidak Memenuhi } \\
\text { Syarat }\end{array}$ & 0 & 0 \\
\hline $\mathbf{2}$ & Memenuhi Syarat & 54 & 100 \\
\hline & Total & 54 & 100 \\
\hline \multicolumn{3}{c}{ Sumber : Data Primer } &
\end{tabular}

Tabel 2

Distribusi Kondisi Sarana Jamban Lembaga Permasyarakatan Perempuan Kelas II A

\begin{tabular}{llcc}
\multicolumn{4}{c}{ Sungguminasa Tahun 2019 } \\
\hline No & Sarana Jamban & $\mathbf{n}$ & $\%$ \\
\hline 1 & $\begin{array}{c}\text { Tidak Memenuhi } \\
\text { Syarat }\end{array}$ & 11 & 20 \\
\hline $\mathbf{2}$ & Memenuhi Syarat & 43 & 80 \\
\hline & Total & 54 & 100 \\
\hline Sumber : Data Primer & & \\
\end{tabular}

Tabel 3

Distribusi Kondisi Sarana Penampungan Sampah Lembaga Permasyarakatan Perempuan Kelas II A Sungguminasa Tahun 2019

\begin{tabular}{cccc}
\multicolumn{4}{c}{ Sungguminasa Tahun 2019 } \\
No & $\begin{array}{c}\text { Sarana } \\
\text { Penampungan } \\
\text { Sampah }\end{array}$ & $\mathbf{n}$ & $\%$ \\
\hline $\mathbf{1}$ & $\begin{array}{c}\text { Tidak Memenuhi } \\
\text { Syarat }\end{array}$ & 6 & 11 \\
\hline $\mathbf{2}$ & Memenuhi Syarat & 48 & 89 \\
\hline & Total & 54 & 100 \\
\hline & Sumber: Data Primer
\end{tabular}

Tabel 4

Distribusi Kondisi Sarana Pembuangan Air Limbah Lembaga Permasyarakatan Perempuan Kelas II A Sungguminasa Tahun 2019

\begin{tabular}{cccc}
\hline \multicolumn{4}{c}{ Sungguminasa Tahun 2019} \\
No & $\begin{array}{c}\text { Sarana } \\
\text { Pembuangan Air } \\
\text { Limbah }\end{array}$ & $\mathbf{n}$ & $\%$ \\
\hline $\mathbf{1}$ & $\begin{array}{c}\text { Tidak Memenuhi } \\
\text { Syarat }\end{array}$ & 6 & 11 \\
\hline $\mathbf{2}$ & Memenuhi Syarat & 48 & 89 \\
\hline & Total & 54 & 100 \\
\hline Sumber : Data Primer & &
\end{tabular}


Tabel 5

Distribusi Kejadian Diare Lembaga

Permasyarakatan Perempuan Kelas II A Sungguminasa Tahun 2019

\begin{tabular}{cccc}
\hline No & Kejadian Diare & Frekuensi & $\%$ \\
\hline $\mathbf{1}$ & $\begin{array}{c}\text { Tidak Menderita } \\
\text { Diare }\end{array}$ & 39 & 72 \\
\hline $\mathbf{2}$ & Menderita Diare & 15 & 28 \\
\hline & Total & 54 & 100 \\
\hline
\end{tabular}

Sumber : Data Primer

2. Analysis Bivariate

Berdasarkan uji Chi square hasil tabulasi menggunakan program SPSS statistik didapatkan variabel air bersih konstan. Hal ini menunjukkan bahwa variabel air bersih tidak ada hubungan dengan kejadian diare, karena menunjukkan kecenderungan semua sampel sarana air bersih memenuhi syarat tidak menderita diare dibandingkan dengan yang tidak memenuhi syarat menderita diare

Tabel 6

Hubungan Sarana Jamban dengan Kejadian Diare Lembaga

Permasyarakatan Perempuan Kelas II A Sungguminasa Tahun 2019

\begin{tabular}{|c|c|c|c|c|c|}
\hline \multirow{3}{*}{$\begin{array}{l}\text { Sarana } \\
\text { Jamba } \\
\mathrm{n}\end{array}$} & \multicolumn{2}{|c|}{ Kejadian Diare } & \multirow{3}{*}{$\begin{array}{l}\text { Jum } \\
\text { lah }\end{array}$} & \multirow{3}{*}{$\%$} & \multirow{3}{*}{$\begin{array}{l}P- \\
\text { val } \\
u e\end{array}$} \\
\hline & Diare & $\begin{array}{l}\text { Tidak } \\
\text { Diare } \\
\end{array}$ & & & \\
\hline & $\mathrm{n}$ & n $\%$ & & & \\
\hline
\end{tabular}

\begin{tabular}{llllllll}
\hline Memen & & & 3 & 79, & 39 & 100 & \\
uhi & 8 & 20,51 & 1 & 49 & & & \\
Syarat & & & & & & & 0,9 \\
Tidak & & & & & & & 67
\end{tabular}

$\begin{array}{lllllll}\begin{array}{l}\text { Memen } \\ \text { uhi }\end{array} & 3 & 20 & 1 & 80 & 15 & 100\end{array}$

Syarat

\begin{tabular}{lllllll}
\hline Total $\quad 11$ & 20,38 & 4 & 79, & 54 & 100 \\
\hline \multicolumn{3}{c}{ Sumber : Data Primer } & 62 & 54
\end{tabular}

Dari uji tabel 6 Chi square hasil tabulasi menggunakan program SPSS statistik didapatkan variabel jamban $p$ value 0,967 dengan $\alpha=0,05$. Hal ini menunjukkan bahwa variabel jamban tidak memiliki hubungan antara sarana jamban dengan kejadian diare di Lembaga Permasyarakatan Perempuan Kelas II A Sungguminasa.
Tabel 7

Hubungan Kondisi Sarana Penampungan Sampah Lembaga Permasyarakatan Perempuan Kelas II A Sungguminasa Tahun 2019

\begin{tabular}{|c|c|c|c|c|c|c|c|}
\hline \multirow{3}{*}{$\begin{array}{c}\text { Sarana } \\
\text { Penampun } \\
\text { gan } \\
\text { Sampah }\end{array}$} & \multicolumn{4}{|c|}{ Kejadian Diare } & \multirow{3}{*}{$\begin{array}{c}\text { Juml } \\
\text { ah }\end{array}$} & \multirow{3}{*}{$\%$} & \multirow{3}{*}{$\begin{array}{c}P- \\
\text { valu } \\
e\end{array}$} \\
\hline & \multicolumn{2}{|c|}{ Diare } & \multicolumn{2}{|c|}{$\begin{array}{l}\text { Tidak } \\
\text { Diare }\end{array}$} & & & \\
\hline & $\mathrm{n}$ & $\%$ & $n$ & $\%$ & & & \\
\hline $\begin{array}{l}\text { Memenuhi } \\
\text { Syarat }\end{array}$ & 5 & $\begin{array}{c}12,8 \\
2\end{array}$ & $\begin{array}{l}3 \\
4\end{array}$ & $\begin{array}{c}87,1 \\
8\end{array}$ & 39 & $\begin{array}{c}10 \\
0\end{array}$ & \\
\hline $\begin{array}{l}\text { Tidak } \\
\text { Memenuhi } \\
\text { Syarat }\end{array}$ & 1 & 6,67 & $\begin{array}{l}1 \\
4\end{array}$ & $\begin{array}{c}93,3 \\
3\end{array}$ & 15 & $\begin{array}{c}10 \\
0\end{array}$ & 9 \\
\hline Total & 6 & $\begin{array}{c}11,1 \\
1\end{array}$ & $\begin{array}{l}4 \\
8 \\
\end{array}$ & $\begin{array}{c}88,8 \\
9\end{array}$ & 54 & $\begin{array}{c}10 \\
0 \\
\end{array}$ & \\
\hline
\end{tabular}

Dari uji tabel 7 Chi square hasil tabulasi menggunakan program SPSS statistik didapatkan variabel jamban $p$ value 0,519 dengan $\alpha=0,05$. Hal ini menunjukkan bahwa variabel jamban tidak memiliki hubungan antara sarana penampungan sampah dengan kejadian diare di Lembaga Permasyarakatan Perempuan Kelas II A Sungguminasa.

Tabel 8

Hubungan Kondisi Sarana Pembuangan Air Limbah Lembaga Permasyarakatan Perempuan Kelas II A Sungguminasa Tahun 2019

\begin{tabular}{|c|c|c|c|c|c|c|c|}
\hline \multirow{3}{*}{$\begin{array}{c}\text { Sarana } \\
\text { Pembuang } \\
\text { an Air } \\
\text { Limbah }\end{array}$} & \multicolumn{4}{|c|}{ Kejadian Diare } & \multirow{3}{*}{$\begin{array}{c}\text { Juml } \\
\text { ah }\end{array}$} & \multirow{3}{*}{$\%$} & \multirow{3}{*}{$\begin{array}{l}P- \\
\text { va } \\
\text { lu } \\
e\end{array}$} \\
\hline & \multicolumn{2}{|c|}{ Diare } & \multicolumn{2}{|c|}{$\begin{array}{l}\text { Tidak } \\
\text { Diare } \\
\end{array}$} & & & \\
\hline & $n$ & $\%$ & $\mathrm{n}$ & $\%$ & & & \\
\hline $\begin{array}{l}\text { Memenuhi } \\
\text { Syarat }\end{array}$ & 4 & 10,3 & 35 & $\begin{array}{c}89 \\
7\end{array}$ & 39 & 100 & 0 \\
\hline $\begin{array}{c}\text { Tidak } \\
\text { Memenuhi } \\
\text { Syarat } \\
\end{array}$ & 2 & 13,3 & 13 & $\begin{array}{c}86 \\
7\end{array}$ & 15 & 100 & $\begin{array}{l}74 \\
7\end{array}$ \\
\hline Total & 6 & $\begin{array}{c}11,1 \\
1\end{array}$ & 48 & $\begin{array}{l}88 \\
89\end{array}$ & 54 & 100 & \\
\hline
\end{tabular}

Berdasarkan uji tabel 8 Chi square hasil tabulasi menggunakan program SPSS statistik didapatkan variabel jamban $p$-value 0,747 dengan $\alpha=0,05$. Hal ini menunjukkan bahwa variabel jamban tidak memiliki hubungan antara sarana pembuangan air limbah dengan kejadian diare di Lembaga Permasyarakatan Perempuan Kelas II A Sungguminasa. 


\section{PEMBAHASAN}

Air adalah elemen yang penting dalam kehidupan manusia. Manusia akan lebih cepat meninggal karena kekurangan air dari pada kekurangan makanan. Dalam tubuh manusia itu sendiri sebagian besar terdiri dari air. Tubuh orang dewasa, sekitar 55$60 \%$ berat badan terdiri dari air, untuk anakanak sekitar $65 \%$, dan untuk bayi sekitar $80 \%$.

Kondisi sarana air bersih di Lembaga Permasyarakatan Perempuan Kelas II A Sungguminasa secara fisik untuk variabel bau tidak berbau dan untuk bak penampungan air kedap air, bersih tetapi tidak tertutup. Berdasarkan hasil wawancara dari salah satu pegawai bahwa sumber air yang digunakan di Lembaga Permasyarakatan Perempuan Kelas II A Sungguminasa menggunakan air PDAM dan telah diuji secara fisik, kimia, maupun biologi bahwa memenuhi syarat untuk digunakan setiap harinya.

Berdasarkan hasil penelitian Muh. Saleh dan Lia tahun 2014 menunjukaan ada hubungan jamban keluarga dan saluran air limbah dengan kejadian diare, dan tidak ada hubungan penyediaan air bersih dan tempat sampah dengan kejadian diare. Sehingga hasil yang diperoleh dari penelitian sebelumnya sejalan dengan hasil yang diperoleh peneliti.

Berdasarkan hasil penelitian Meithyra, dkk tahun 2014 menunjukaan tidak ada hubungan yang signifikan antara kondisi jamban keluarga dengan kejadian diare pada balita di Kelurahan Terjun. Penelitian ini sejalan dengan hasil penelitian tentang hubungan sanitasi jamban dan air bersih dengan kejadian diare pada anak balita di Kelurahan Terjun Kecamatan Medan Marelan Kota Medan Tahun 2014.

Jamban atau kakus merupakan salah satu kebutuhan pokok manusia. Jamban yang lebih dikenal dengan WC dapat menjadi sumber penyebaran penyakit baik secara langsung maupun tidak langsung bila tidak memenuhi syarat kesehatan.

Penggunaan jamban disetiap kamar menggunakan jamban leher angsa, jenis jamban ini merupakan model terbaik yang dianjurkan kesehatan lingkungan. Penggunaan jamban jenis leher angsa ini akan mencegah bau busuk serta masuknya binatang kecil. Oleh karena, itu kondisi jamban yang tidak memenuhi syarat disini tidak begitu berpengaruh terhadap kejadian diare di Lembaga Permasyarakatan Perempuan Kelas II A Sungguminasa, untuk penggunaan air disetiap WC ada beberapa kamar yang menggunakan air bersih tidak cukup setiap harinya dan tidak semua responden yang membersihkan jamban setiap kali selesai BAB.

Dilihat dari hasil yang didapatkan yang memenuhi syarat masih ada yang menderita diare, dikarenakan perilaku dari responden sendiri yang kurang menjaga kebersihannya. Kebiasaan mencuci tangan sebelum dan setalah melakukan kegiatan, apa lagi setelah buang air besar. Tinja dapat mencemari tangan atau jari-jari manusia selanjutnya dapat mencemari makanan pada waktu memasak atau menyiapkan makanan, demikian juga yang telah tercemar dapat langsung kontak dengan mulut.

Berdasarkah hasil penelitian Azmi, dkk tahun 2018 ada hubungan pemanfaatan jamban, penyediaan air bersih, dan pembuangan sampah dengan kejadian diare pada anak balita. Akan tetapi, penelitian ini tidak sejalan dengan hasil penelitian tentang hubungan sanitasi lingkungan dengan kejadian diare pada anak balita di wilayah kerja puskesmas Bambaira Kabupaten Pasangkayu khususnya pembuangan sampah.

Beberapa faktor yang mempengaruhi tidak berhubungan penampungan sampah dengan kejadian diare dimana seiap kamar memiliki penampungan sampah, hanya saja disetiap kamar ada yang terdapat dua tempat sampah yang memisahkan sampah basah (organik) dan sampah kering (anorganik) dan ada yang memiliki satu tempat sampah saja. Sampah basah (organik) yang dihasilkan hanya berasal dari sisa makanan, sedangkan sampah kering (anorganik) bersal dari plastik makanan dan botol minuman. Hal ini memudahkan para responden untuk memilah sampah anorganik yang akan didaur ulang.

Adapun yang menggunakan tempat sampah yang tidak berkonstruksi kuat dan tidak kedap air, begitu juga sebailikya ada yang menggunakan tempat sampah yang berkonstruksi kuat dan kedap air, penampungan sampah tersebut terletak di depan kamar responden tidak ada tempat sampah yang berada di dalam kamar responden dan tidak semua memiliki penutup. Berdasarkan wawancara dari salah satu pegawai pengangkutan sampah 
dilakukan setiap hari, tetapi untuk sampah yang berupa botol bekas dikumpulkan untuk dapat didaur ulang.

Asumsi penliti masih kurangnya kebiasaan bagi narapida untuk selalu menjaga kebersihan dirinya, perilaku mencuci tangan sebelum dan sesudah makan yang menjadi faktor terjadinya diare. Masih didapatkan tempat sampah terbuka yang dapat mengundang vektor penyakit. Telah diketahui bahwa sampah tempatnya vektor penyakit seperti lalat, dimana lalat mempunyai kebiasaan hinggap dimakanan tanpa disadari dimakan oleh manusia.

Berdasarkan hasil penelitian Sarnita, dkk tahun 2017 menunjukaan ada hubungan antara sarana penyediaan air bersih, pembuangan air limbah, sarana pembuangan sampah, sarana pembuangan tinja, dan kepadatan lalat dengan kejadian diare balita. Akan tetapi, penelitian ini tidak sejalan dengan hasil penelitian tentang faktor yang berhubungan dengan kejadian diare pada balita di wilayah kerja puskesmas abeli bagian pesisir Kota Kendari tahun 2017 khususnya pada air limbah.

Air limbah atau air kotoran adalah air yang tidak bersih dan mengandung berbagai zat yang bersifat membahayakan manusia atau hewan dan lazimnya muncul karena hasil perbuatan manusia.

Salah satu faktor yang menyebabkan sarana pembuangan air limbah yang tidak memenuhi syarat bahwa ada beberapa responden saluran air limbahnya menimbulkan bau hal ini disebabkan karena kurangnya perhatian karena membersihkan saluran air limbahnya satu kali dalam satu minggu. Ada beberapa responden yang didapatkan saluran air limbah kurang lancar hal ini dikarenakan terdapat kotoran seperti kertas yang terdapat diselokan. Hal ini menyebabkan saluran air limbah merupakan sumber beberapa penyakit.

\section{KESIMPULAN}

Tidak ada hubungan kondisi sarana sanitasi lingkungan dengan kejadian diare di Lembaga Permasyarakatan Perempuan Kelas II A Sungguminasa, hasil uji Chi Square $p>0,05$.

\section{SARAN}

1. Bagi pengelola lembaga permasyarakatan meningkatkan kondisi sarana sanitasi lingkungan yang memenuhi standar kesehatan sebagai wujud peningkatan kesehatan.

2. Bagi warga binaan permasyarakatan meningkatkan kebiasaan mencuci tangan sebelum dan setelah melakukan kegiatan menggunakan air mengalir dan sabun untuk menimalisir penyakit diare.

\section{DAFTAR PUSTAKA}

Ariani. Putri. Ayu. 2016. Diare Pencegahan dan Pengobatannya. Nuha Yogyakarta : Medika.

Azmi, dkk. 2018. Hubungan Sanitasi Lingkungan dengan Kejadian Diare pada Anak Balita di Wilayah Kerja Puskesmas Bambaira Kabupaten Pasangkayu. Palu : Fakultas Kesehatan Masyarakat. Universitas Muhammadiyah Palu. (Online) http://download.garuda.ristekdikti. go.id/article. php? article $=834081 \& \mathrm{val}=13128 \&$ title=HUBUNGAN\%20SANITASI\%20LINGK UNGAN\%20DENGAN\%20KEJADIAN\%20DIARE\%20PADA\%20ANAK\%20BALITA\%20D I\%20WILAYAH\%20KERJA\%20PUSKESMAS\%20BAMBAIRA\%20KABUPATEN\%20PAS ANGKAYU. Diakses pada 16 Juni 2019

Azwinsyah, dkk. 2014. Faktor-Faktor Yang Berhubungan Dengan Rendahnya Kepemilikan Jamban Keluarga Dan Personal Hygiene Dengan Kejadian Diare Di Desa Sei Musam Kendit Kecamatan Bahorok Kabupaten Langkat Tahun 2014. Skripsi : USU. (Online) https://media.neliti.com/media/publications/14548-ID-faktor-faktor-yang-berhubungandengan-rendahnya-kepemilikan-jamban-keluarga-dan.pdf. Diakses pada 10 Mei 2019

Chandra. Budiman. 2006. Pengantar Kesehatan Lingkungan. Jakarta : EGC.

Depkes R.I. 2010. Pedoman Pemberantasan Penyakit Diare. Jakarta : Ditjen PPM dan PL.

Dinas Kesehatan Kabupaten Gowa. 2016. Profil Kesehatan Kabupaten Gowa Tahun 2016. Gowa : Dinas Kesehatan Kabupaten Gowa.

Hardiyanti. E. A. 2008. Indikator Perbaikan Kesehatan Lingkungan Anak. Jakarta : EGC.

Kementerian Kesehatan RI. 2016. Profil Kesehatan Indonesia Tahun 2016. Jakarta : Kementerian Kesehatan RI.

Masriadi. 2017. Epidemiologi Penyakit Menular. Depok : PT Rajagrafindo Persada. 
Jurnal Sulolipu : Media Komunikasi Sivitas Akademika dan Masyarakat

Vol. 20 No. 12020

e-issn : 2622-6960, p-issn : 0854-624X

Mbolosi. Anwar. 2010. Hubungan Sanitasi Lingkungan dengan Kejadian Diare pada Masyarakat Desa Kaofe Kecamatan Kadatua Kabupaten Buton Tahun 2010. Skripsi. Makassar : Fakultas IImu Kesehatan Universitas Islam Negeri Alauddin Makassar. (Online) http://repositori.uin-alauddin.ac.id/6507/1/Anwar\%20Mbolosi_opt.pdf. Diakses pada 10 Mei 2019

Melviana. M.S, dkk. 2014. Hubungan Sanitasi Jamban dan Air Bersih dengan Kejadian Diare pada Balita di Kelurahan Terjun Kecamatan Medan Marelan Kota Medan Tahun 2014. Medan : Fakultas Kesehatan Masyarakat. USU. (Online) https://media.neliti.com/ media/publications/14517-ID-hubungan-sanitasi-jamban-dan-air-bersih-dengan-kejadian diare-pada-balita-di-kel.pdf. Diakses pada 15 Juni 2019

Mubarak. W.I. Nurul. Chayatin. 2009. IImu Kesehatan Masyarakat. Salemba Jakarta : Medika.

Mulia. R.M. 2005. Kesehatan Lingkungan. Yogyakarta : Graha IImu.

Muntu. Ronny. 2008. Penyehatan Air dan Limbah Cair-A (PAPLC-A). Makassar : Poltekkes Kemenkes Republik Indonesia Jurusan Kesehatan Lingkungan.

Nugraheni. Devi. 2012. Hubungan Kondisi Fasilitas Sanitasi Dasar dan Personal Hygiene dengan Kejadian Diare di Kecamatan Semarang Utara Kota Semarang. Jurnal $\begin{array}{llllll}\text { Kesehatan } & \text { Masyarakat. } & 1 & \text { (2) } & \text { 922-933 (Online) }\end{array}$ https://media.neliti.com/media/publications/8723-ID-hubungan-kondisi-fasilitas-sanitasidasar-dan-personal-hygiene-dengan-kejadian-d.pdf. Diakses pada 17 Desember 2018

Nurnanigsih. Sarnita, dkk. 2017. Faktor-faktor yang Berhubungan dengan Kejadian Diare pada Balita di Wilayah Kerja Puskesmas Abeli Bagian Pesisir Kota Kendari Tahun 2017. Jurnal IImiah Kesehatan Masyarakat. 2 (6) : 250-731 (Online) https://media.neliti.com/media/ publications/198354-faktor-yang-berhubungan-dengan-kejadian.pdf. Diakses pada 16 Juni 2019

Nurlina. Andi. 2013. Kondisi Sanitasi Dasar Rumah Susun di Kecamatan Mariso Kota Makassar. (Karya Tulis IImiah) tidak dipublikasikan. Makassar : Jurusan Kesehatan Lingkungan Poltekkes Makassar.

Rahman, dkk. 2016. Faktor-faktor yang Berhubungan dengan Kejadian Diare di Desa Solor Kecamatan Cermee Bondowoso. Jurnal. 1 (1) : 25-35. (Online) https://media.neliti.com/media/publications/197123-ID-factors-related-to-diarrhea-in-solorvil.pdf. Diakses pada 12 Januari 2019

Ramidha. R.S. 2011. Evaluasi Sanitasi Lingkungan Institusi Lembaga Permasyarakatan Klas 1 Kota Madiun. Skripsi. Universitas Airlangga Fakultas Kesehatan Masyarakat : Surabaya (Online) http://repository.unair.ac.id/22890/1/gdlhub-gdl-s1-2011-ramidharat-20266fkm551-k.pdf. Diakses pada 13 Januari 2019

Republik Indonesia. 2017. Peraturan Menteri Kesehatan Republik Indonesia Nomor 32 Tahun 2017 Tentang Standar Baku Mutu Kesehatan Lingkungan dan Persyaratan Kesehatan untuk Keperluan Higiene Sanitasi, Kolam Renang, Solus Per Aqua, dan Permandian Umum.

Republik Indonesia. 2014. Peraturan Menteri Kesehatan Republik Indonesia Nomor 3 Tahun 2014 Tentang Sanitasi Total Berbasis Masyarakat.

Republik Indonesia. 2012. Peraturan Menteri Lingkungan Hidup Republik Indonesia Nomor 13 Tahun 2012 Tentang Pedoman Pelaksanaan Reduce, Reuse, dan Recycle Melalui Bank Sampah

Sahani. Wahyuni, dkk. 2018. Panduan Penulisan Proposal Penelian dan SKRIPSI. Makassar : Poltekkes Kemenkes Republik Indonesia Jurusan Kesehatan Lingkungan.

Saleh. Muh. Rachim. L.H. 2014. Hubungan Kondisi Sarana Sanitasi Lingkungan dengan Kejadian Diare pada Anak Balita di Wilayah Kerja Puskesmas Baranti Kabupaten Sidrap Tahun 2013. 7 (1) : 222. (Online) https://media.neliti.com/media/publications/218825hubungan-kondisi-sanitasi-lingkungan-den.pdf. Diakses 17 Desember 2018

Sari. Rachmayana. 2013. Ketersediaan dan Kondisi Sarana Sanitasi di Lingkungan Permukiman Kumuh. (Karya Tulis Imilah) tidak dipublikasikan. Makassar : Jurusan Kesehatan Lingkungan.

Setiyabudi. Ragil. Veronika. S. 2016. Penyediaan Air Bersih, Penggunaan Jamban Keluarga, Pengelolaan Sampah, Sanitasi Makanan, dan Kebiasaan Mencuci Tangan Berpengaruh Terhadap Kejadian Diare Umur 15-50 TH. Jurnal IImiah IImu-IImu Ksehehatan. 14 (2) : 
Jurnal Sulolipu : Media Komunikasi Sivitas Akademika dan Masyarakat

Vol. 20 No. 12020

e-issn : 2622-6960, p-issn : 0854-624X

41-42 (Online) file:///C:/Users/ilo/Downloads/1054-7818-1-PB.pdf. Diakses pada 8 Juni 2019

Surharyono. 2008. Diare Akut Klinik dan Laboratorik. Jakarta : Rineka Cipta.

Susi. Hartati, Nurazila. 2018. Faktor yang Mempengaruhi Kejadian Diare pada Balita di Wilayah Kerja Puskesmas Rejosari Pekanbaru. Akademi Kebidanan Sempena Negeri Pekanbru. 3 (2) : 400-407 (Online) file:///C:/Users/ilo/Downloads/2962-11871-2-PB.pdf. Diakses 12 Januari 2019

Panjaitan, Irwan, dkk. 2008. Pembaharuan Pemikiran DR. Sahardjo mengenai Pemasyarakatan Narapida. Jakarta : CV. Indhill Co.

Pemerintah Kota Makassar Dinas Kesehatan. 2015. Profil Kesehatan Makassar Tahun 2015. Makassar : Pemerintah Kota Makassar Dinas Kesehatan.

Primona, dkk. 2013. Faktor-Faktor Yang Berhubungan Dengan Kejadian Diare Pada Anak Usia 0-59 Bulan Di Wilayah Kerja Puskesmas Simarmata Kecamatan Simanindo Kabupaten Samosir Tahun 2013. Skripsi : USU. (Online) http://repository.usu.ac.id/bitstream/handle/ 123456789/61111/Cover.pdf?sequence=7\&isAllowed=y. Diakses pada 12 Januari 2019

Purnama. S.G. 2016. Penyakit Berbasis Lingkungan. Bandung : Penerbit Alfabeta

Yusriani. Hajrah. 2009. Tinjauan Konstruksi Kamar Lembaga Permasyarakatan Klas I A Makassar. (Karya Tulis IImiah) tidak dipublikasikan. Makassar : Jurusan Kesehatan Lingkungan Poltekkes Makassar.

Zahrah. A. S. 2018. Makalah Praktikum Preskripsi Diare. Universitas Muhammadiyah Malang. Jurusan Studi Farmasi : Malang. (Online) https://www.academia.edu/36712509/MAKALAH_TENTANG_DIARE.pdf. Diakses pada 12 Januari 2019

Zein. Umar, dkk. 2004. Diare Infeksi Bakteri. Fakultas Kedokteran Divisi Penyakit Tropik dan Infeksi Bagian IImu Penyakit Dalam. Universitas Sumatera Utara. (Online) https://www.researchgate.net/publication/ 42321299_Diare_Akut_Disebabkan_Bakteri. Diakses pada 12 Januari 2019 